\title{
Muerte súbita asociada a miocardiopatía arritmogénica.
}

Suden death due to arrhythmogenic cardiomyopathy.

\section{P. Guillén Navarro y cols. \\ Cuad Med Forense 2000;21:31-35}

Varón de 22 años, sin antecedentes patológicos conocidos, deportista, que en el curso de un entrenamiento en el gimnasio se marea y pierde el conocimiento. En el servicio de urgencias del hospital donde es trasladado detectan fibrilación ventricular siendo sometido a maniobras de reanimación cardiopulmonar sin éxito. Un mes antes se le había practicado un ecocardiograma como parte de una exploración cardiológica requerida por la federación que resultó dentro de la normalidad. En la autopsia destacaba: corazón de 364 g, de aspecto globoso (Figura $n^{\circ}$ I), de consistencia reblandecida, estando a la palpación la pared del ventrículo derecho fláccida y adelgazada, incluso en algunas zonas queda reducido a trabéculas, en algunas zonas el espesor del ventrículo derecho era de $3 \mathrm{~mm}$ (Figura $\mathrm{n}^{\circ} 2$ ). El espesor de la pared libre del ventículo izquierdo y tabique interventricular era de $15 \mathrm{~mm}$. En el estudio microscópico del corazón se puso de manifiesto la presencia de amplio reemplazo de los miocitos por tejido fibroadiposo en la pared del ventrículo derecho. Igualmente se evidenciaba este hallazgo a nivel subepicárdico de la cara postero-lateral del ventrículo izquierdo. El diagnóstico anatomopatológico fue: Miocardiopatía arritmogénica con compromiso biventricular, con mayor afectación del ventrículo derecho.

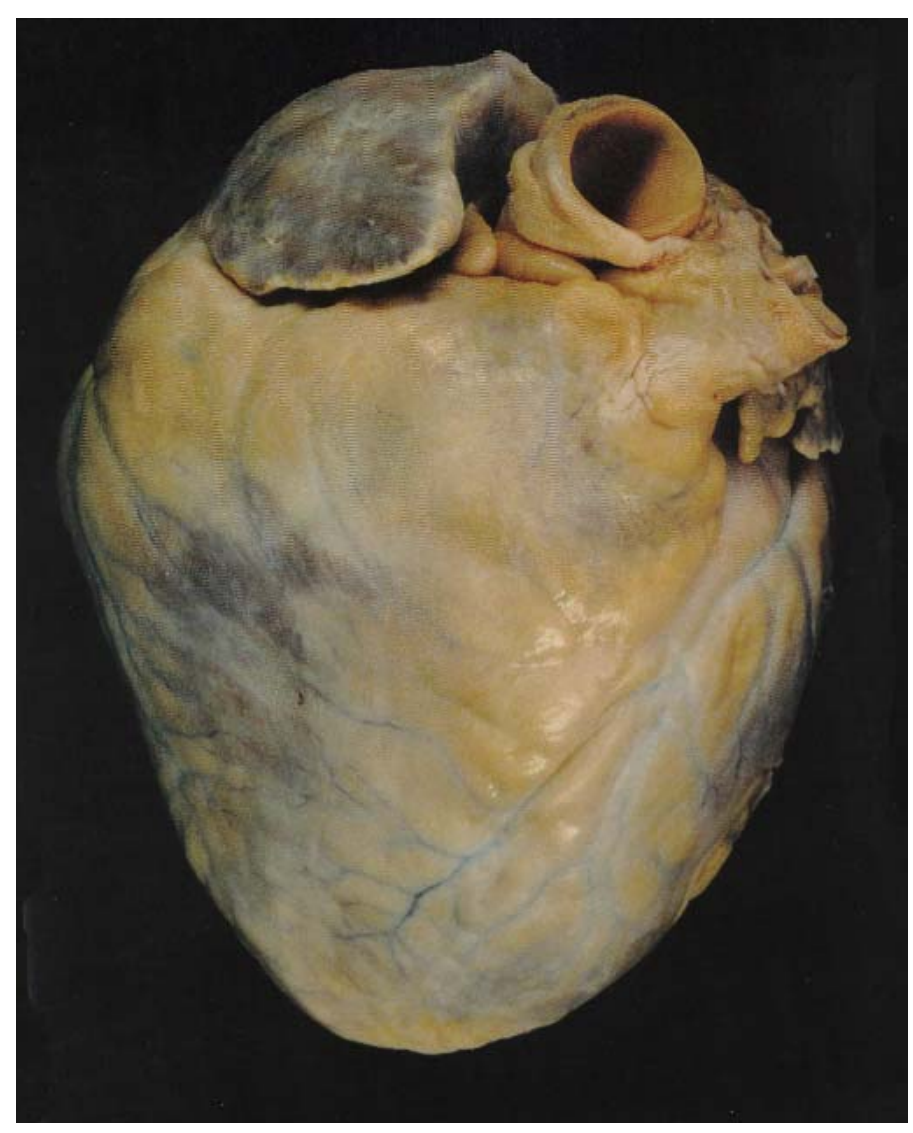

Figura 1.- Corazón de aspecto globoso. 


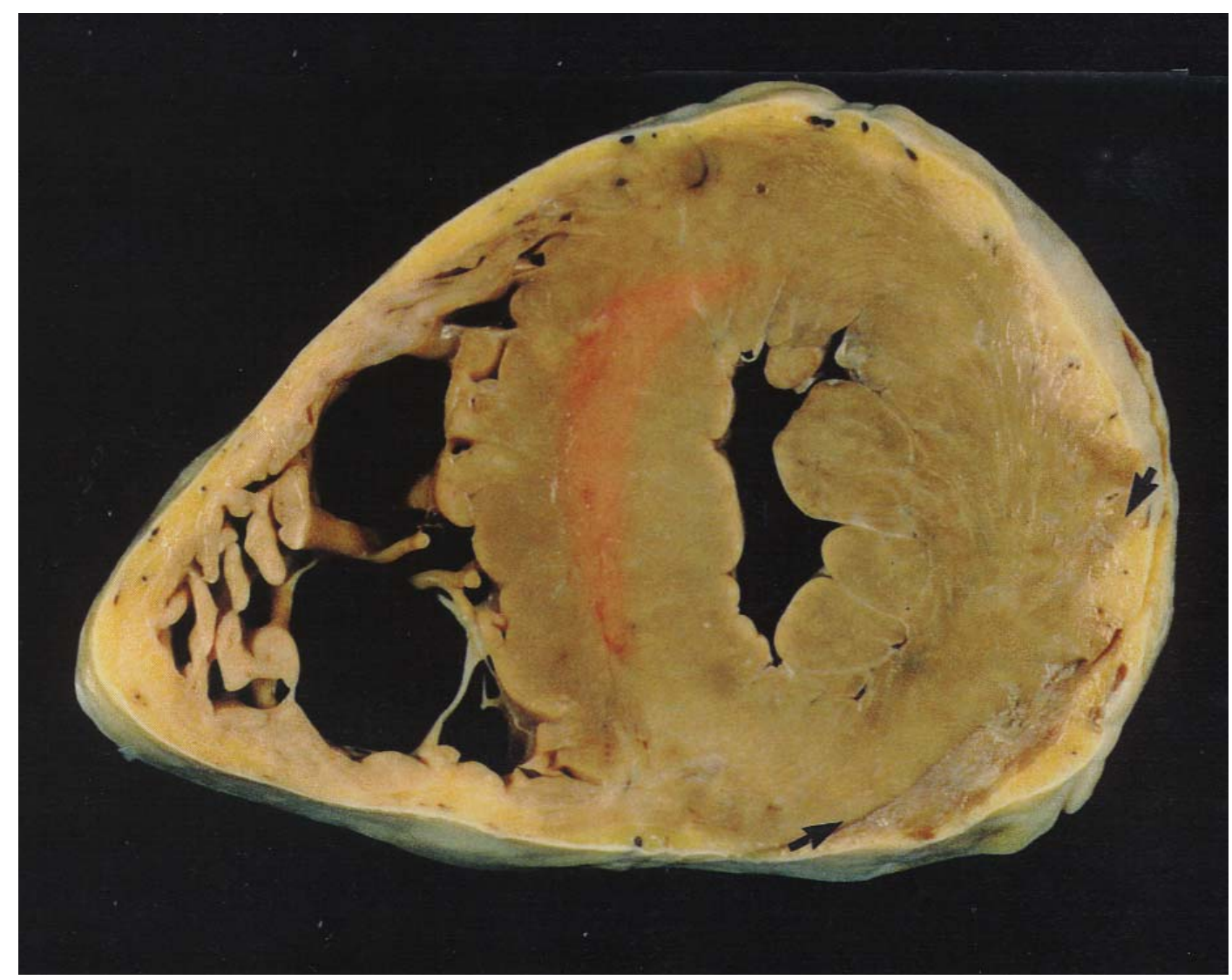

Figura 2.- Corte transversal a nivel de tercio medio de los ventrículos. Se puede apreciar la sustitución por grasa del miocardio del ventrículo derecho, especialmente en la cara anterior. En la región subepicárdica postero-lateral del ventrículo izquierdo hay reemplazo por tejido fibro-adiposo. 